\title{
In situ Formation of Multifunctional DNA Nanospheres for Sensitive and Accurate Dual-Mode Biosensor with Photoelectrochemical and Elecreochemical Assay
}

\author{
Hanmei Deng, Yaqin Chai, Ruo Yuan, Yali Yuan* \\ Chongqing Engineering Laboratory of Nanomaterials \& Sensor Technologies, \\ College of Chemistry and Chemical Engineering, Southwest University, \\ Chongqing 400715 \\ * Corresponding author. Tel.: +86-23-68252277; Fax: +86-23-68253172. \\ E-mail address: y198688@swu.edu.cn.
}

Contents of the Supporting Information:

Reagents and Materials----S-2

Apparatus----S-3

Investigation of the Band Gap (Eg) and Energy Levels of Materials----S-4

Preliminary Application of the Biosensor in Human Serum-----S-6

Other Tables----S-7 


\section{Reagents and Materials}

Perylene-3, 4, 9, 10-tetracarboxylic dianhydride (PTCDA) was purchased from LianGang Dyestuff Chemicals Co. Ltd (Liaoning, China). Sodium hydroxide ( $\mathrm{NaOH})$ was provided by Kelong Co. Ltd (Chengdu, China). Iodoethane $\left(\mathrm{C}_{2} \mathrm{H}_{5} \mathrm{I}\right)$ and isobutanol $\left(\mathrm{C}_{4} \mathrm{H}_{10} \mathrm{O}\right)$ were supplied by Macklin Biochemical Co. Ltd (Shanghai, China). 3-dimethylaminopropylamine (DMAPA, $\mathrm{C}_{5} \mathrm{H}_{14} \mathrm{~N}_{2}$ ) was purchased by TCI Development Co. Ltd. (Shanghai, China). Ascorbic acid (AA) was obtained from Sinopharm Chemical Reagent Co. Ltd (Shanghai, China). Gold chloride $\left(\mathrm{HAuCl}_{4}\right)$ and hexanethiol (HT) were purchased from Sigma Chemical Co. (St. Louis. MO, USA). The human serum was obtained by Xinqiao Hospital. Phi-29 DNA polymerase was brought from Vazyme Biotech Co. Ltd (Nanjing, China). Phosphate buffered solution (PBS, pH 7.0) was prepared by $0.1 \mathrm{M} \mathrm{Na}_{2} \mathrm{HPO}_{4}, 0.1 \mathrm{M} \mathrm{KH}_{2} \mathrm{PO}_{4}$ and $0.1 \mathrm{M}$ KCl. Tris- $\mathrm{HCl}$ buffer was prepared by $20 \mathrm{mM}$ tris- $\mathrm{HCl}, 140 \mathrm{mM} \mathrm{NaCl}, 5 \mathrm{mM} \mathrm{KCl}$ and $1 \mathrm{mM} \mathrm{CaCl}_{2} \cdot \mathrm{T}_{4}$ DNA ligase, dNTPs, $\mathrm{T} 7$ exonuclease and the oligonucleotides were obtained by Sangon Biotech Co. Ltd (Shanghai, China). The corresponding information of oligonucleotide sequences was listed as follows:

Table S1. Information of oligonucleotide sequences in this experiment

\begin{tabular}{cl}
\hline \hline Name & \multicolumn{1}{c}{ Sequence (5'-3') } \\
\hline Template & P'-TTG ATG CTG CAG CGA TAG ATG GGC GTA CGT TAT CGC \\
& TTT GTC TGT TCT \\
$\mathbf{Y}_{\mathbf{1}}$ & SH-TTT TTT TGC AGC ATC AAA GAA CAG ACA \\
$\mathbf{Y}_{\mathbf{2}}$ & CCA TCT TTA CCG TTC TTT GAT GCT GC \\
miRNA-14 & UAA CAC UGU CUG GUA AAG AUG G \\
$\mathbf{1}$ & \\
miRNA-21 & UAG CUU AUC AGA CUG AUG UUG A \\
miRNA-15 & UUA AUG CUA AUC GUG AUA GGG GU \\
$\mathbf{5}$ &
\end{tabular}




\section{TP 53 GAG GTT GTG AGG CGC TGC CCC CAC CAT G}

\section{Apparatus}

PEC measurement was conducted under $0.0 \mathrm{~V}$ potential by a PEC workstation (Ivium, Netherlands) in PBS containing $0.1 \mathrm{M}$ ascorbic acid (AA), light source of which was provided with LED lamp. CHI 660e electrochemical workstation (Shanghai Chenhua Instrumission, China) was used to accomplish electrodeposition, DPV measurement and EIS measurement. Electrodeposition of AuNPs was performed in $1 \% \mathrm{~W} / \mathrm{V} \mathrm{HAuCl}_{4}$ aqueous solution at $-0.2 \mathrm{~V}$ constant potential. DPV measurements were performed in 0.1 M PBS ( $\mathrm{pH} 7.0)$ at room temperature with the potential from $-0.1 \mathrm{~V}$ to $-0.6 \mathrm{~V}$, the corresponding parameters about sweeping rate, pulse amplitude, pulse width and pulse period were $50 \mathrm{mV} / \mathrm{s}, 20 \mathrm{mV}, 50 \mathrm{~ms}$ and $2 \mathrm{~s}$, respectively. EIS measurements were performed in $5.0 \mathrm{mM}\left[\mathrm{Fe}(\mathrm{CN})_{6}\right]^{3-/ 4-}$ with the initial voltage of $0.22 \mathrm{~V}$, the high frequency and low frequency respectively were $100000 \mathrm{~Hz}$ and 0.1 $\mathrm{Hz}$, and the amplitude was $0.005 \mathrm{~V}$. The morphologies of diverse materials were taken by scanning electron microscopy (SEM, S-4800, Hitachi, Japan). The polyacrylamide gel electrophoresis was characterized with BG-ver MIDI electrophoresis apparatus (Baygene, Beijing, China) and the image of gels was implemented by Doc XR+ system (Bio-Rad, California, USA). 


\section{Investigation of the Band Gap (Eg) and Energy Levels of Materials}

The band gap $(E \mathrm{~g})$ and energy levels of $\mathrm{PDA}^{+}$and $\mathrm{TiO}_{2}$ was investigated via the optical and electrical measurements. ${ }^{1,2}$ The ultraviolet-visible (UV-vis) absorption spectrum from the visible region to near-infrared zone was shown in Figure S1A, in which the cutoff wavelength of $\mathrm{PDA}^{+}\left(\lambda_{\mathrm{PDA}^{+}}\right)$and the cutoff wavelength of $\mathrm{TiO}_{2}\left(\lambda_{\mathrm{TiO} 2}\right)$ were respectively located at $580 \mathrm{~nm}$ and $540 \mathrm{~nm}$ for estimating the value of $E \mathrm{~g}$. Based on classical formula eq 1, the $E \mathrm{~g}$ of $\mathrm{PDA}^{+}$and $\mathrm{TiO}_{2}$ were calculated as $2.14 \mathrm{eV}$ and $2.30 \mathrm{eV}$, respectively.

$$
E \mathrm{~g}=1240 / \lambda_{\text {cutoff }}
$$

Additionally, the energy levels were further investigated. The lowest unoccupied molecular orbital (HOMO) of $\mathrm{PDA}^{+}$and the valence band (VB) of $\mathrm{TiO}_{2}$ were determined by calculating their ionization potential (IP). Similarly, the highest occupied molecular orbital (LUMO) and the conduction band (CB) were counted according to the electron affinity (EA) as follow:

$$
\begin{aligned}
& \mathrm{IP}=-\left(4.80-E_{1 / 2}{ }^{\mathrm{Fc} / \mathrm{Fc}^{+}}+E_{\mathrm{ox}}\right) \\
& \mathrm{EA}=\mathrm{IP}+E \mathrm{~g}
\end{aligned}
$$

Where the $E_{1 / 2}{ }^{\mathrm{Fc} / \mathrm{Fc}+}$ represent the formal potential of the ferrocene as the reference substrate with an assumed vacuum level of $4.8 \mathrm{eV}$, and the $E_{\mathrm{ox}}$ refers to oxidation potentials. As shown in Figure $\mathrm{S} 1 \mathrm{~B}$, the oxidation peaks of $\mathrm{PDA}^{+}$and $\mathrm{TiO}_{2}$ were respectively disclosed as $0.6 \mathrm{eV}$ and $0.8 \mathrm{eV}$ at cyclic voltammetry (CV) curve. Based on aforementioned formulas, the HOMO/LUMO of $\mathrm{PDA}^{+}$was thus calculated as 
$-4.92 \mathrm{eV}$ (eq 2) and $-2.78 \mathrm{eV}$ (eq 3), herein the $\mathrm{VB} / \mathrm{CB}$ was estimated as $-5.12 \mathrm{eV}$ and $-2.82 \mathrm{eV}$ for $\mathrm{TiO}_{2}$. All values including measurement results, estimated $E \mathrm{~g}$, HOMO/LUMO and VB/CB levels were elaborated in Table S2.
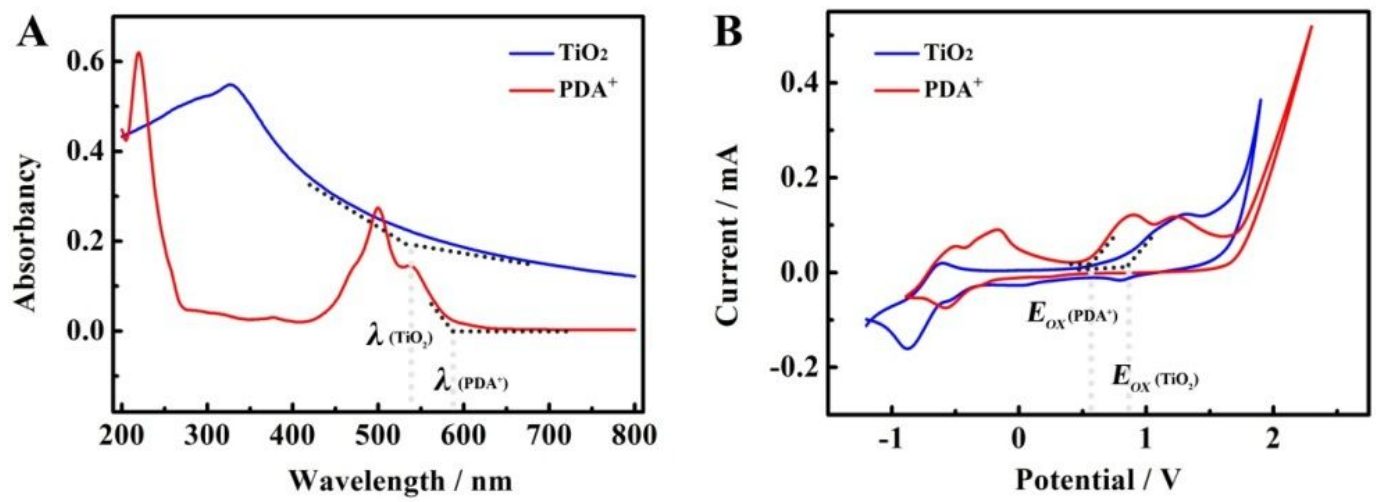

Figure S1. (A) The UV-vis absorption spectrum and (B) the CV curves of $\mathrm{TiO}_{2}$ and $\mathrm{PDA}^{+}$.

Table S2. The value of the band gap $(E \mathrm{~g})$ and energy levels of materials.

\begin{tabular}{|c|c|c|c|c|c|}
\hline Materials & $\boldsymbol{\lambda}_{\text {cutoff }}$ & $\boldsymbol{E g}$ & $\boldsymbol{E}_{\mathbf{0 x}}$ & HOMO/VB & LUMO/CB \\
\hline $\mathbf{T i O}_{\mathbf{2}}$ & $540 \mathrm{~nm}$ & $2.30 \mathrm{eV}$ & $0.8 \mathrm{eV}$ & $-5.12 \mathrm{eV}$ & $-2.82 \mathrm{eV}$ \\
\hline $\mathbf{P D A}^{+}$ & $580 \mathrm{~nm}$ & $2.14 \mathrm{eV}$ & $0.6 \mathrm{eV}$ & $-4.92 \mathrm{eV}$ & $-2.78 \mathrm{eV}$ \\
\hline
\end{tabular}




\section{Preliminary Application of the Biosensor in Human Serum}

To assess the applicability of proposed dual-mode biosensor, standard addition method was adopted. Different concentrations of miRNA-141 (5 fM, $10 \mathrm{fM}, 1 \mathrm{pM}, 10$ $\mathrm{pM}$ and $100 \mathrm{pM}$ ) were prepared with the 40 -fold diluted human serum to measure content. As shown in table S3, the recoveries of miRNA-141 were respectively calculated to be $108.5 \%, 90.93 \%, 93.47 \%, 96.86 \%$ and $102.1 \%$ with a relative standard deviation (RSD) from $1.3 \%$ to $5.6 \%$, which demonstrated that the potential application of the fabricated biosensor in clinical determination research.

Table S3. Recovery research of miRNA-141 in human serum.

\begin{tabular}{cccc}
\hline $\begin{array}{c}\text { added } \\
\text { concentration }\end{array}$ & $\begin{array}{c}\text { found } \\
\text { concentration }\end{array}$ & recovery & RSD \\
\hline $\mathbf{5} \mathbf{f M}$ & $5.425 \mathrm{fM}$ & $108.5 \%$ & $2.1 \%$ \\
$\mathbf{1 0} \mathbf{~ f M}$ & $9.093 \mathrm{fM}$ & $90.93 \%$ & $1.3 \%$ \\
$\mathbf{1} \mathbf{~ p M}$ & $0.9347 \mathrm{pM}$ & $93.47 \%$ & $3.4 \%$ \\
$\mathbf{1 0} \mathbf{~ p M}$ & $9.686 \mathrm{pM}$ & $96.86 \%$ & $5.6 \%$ \\
$\mathbf{1 0 0} \mathbf{~ p M}$ & $102.1 \mathrm{pM}$ & $102.1 \%$ & $3.8 \%$ \\
\hline \hline
\end{tabular}


Table S4. Comparison of miRNA-141assay with other reported detection methods

\begin{tabular}{cccc}
\hline \hline analytical method & detection limit & linear range & ref \\
\hline SERS & $1 \mathrm{pM}$ & $1 \mathrm{pM}$ to $100 \mathrm{nM}$ & 3 \\
EC & $33.6 \mathrm{fM}$ & $100 \mathrm{fM}$ to $100 \mathrm{nM}$ & 4 \\
FL & $10 \mathrm{fM}$ & $1 \mathrm{pM}$ to $10 \mathrm{nM}$ & 5 \\
\hline SPR & $0.56 \mathrm{fM}$ & $0 \mathrm{pM}$ to $50 \mathrm{pM}$ & 6 \\
ECL & $0.5 \mathrm{fM}$ & $1 \mathrm{fM}$ to $1 \mathrm{nM}$ & 7 \\
CL & $10 \mathrm{pM}$ & $10 \mathrm{pM}$ to $200 \mathrm{nM}$ & 8 \\
PEC & $83 \mathrm{fM}$ & $100 \mathrm{fM}$ to $3 \mathrm{nM}$ & 9 \\
PEC & $0.037 \mathrm{fM}$ & $0.1 \mathrm{fM}$ to $1 \mathrm{nM}$ & Our work \\
EC & $0.67 \mathrm{fM}$ & $2 \mathrm{fM}$ to $500 \mathrm{pM}$ & \\
\hline \hline
\end{tabular}

Abbreviations: electrochemiluminescence (ECL); photoelectrochemical (PEC); fluorescence (FL); electrochemical (EC); surface plasmon resonance (SPR); chemiluminescent (CL)

\section{REFERENCES}

(1) Wang, Q.; Ruan, Y. F.; Zhao, W. W.; Lin, P.; Xu, J. J.; Chen, H. Y. Semiconducting Organic-Inorganic Nanodots Heterojunctions: Platforms for General Photoelectrochemical Bioanalysis Application. Anal. Chem. 2018, 90, 3759-3765.

(2) Wang, H. H.; Li, M. J.; Wang, H. J.; Chai, Y. Q.; Yuan, R. P-n Sensitized Heterostructure $\mathrm{Co}_{3} \mathrm{O}_{4} /$ Fullerene with Highly Efficient Photoelectrochemical Performance for Ultrasensitive DNA Detection. ACS Appl. Mater. Interfaces. 2019, $11,23765-23772$.

(3) Wang, Q.; Li, Q.; Yang, X.; Wang, K.; Du, S.; Zhang, H.; Nie, Y. Graphene Oxide-gold Nanoparticles Hybrids-based Surface Plasmon Resonance for Sensitive Detection of MicroRNA. Biosens. Bioelectron. 2016, 77, 1001-1007.

(4) J Yan, T. T.; Zhu, L. Y.; Ju, H. X.; Lei, J. P. DNA-walker-induced Allosteric S-7 
Switch for Tandem Signal Amplification with Palladium Nanoparticles/metal-organic Framework Tags in Electrochemical Biosensing. Anal. Chem. 2018, 90, 14493-14499. (5) Xiao, M.; Man, T.; Zhu, C.; Pei, H.; Shi, J.; Li, L.; Qu, X.; Shen, X.; Li, J. MoS 2 Nanoprobe for MicroRNA Quantification Based on Duplex-specific Nuclease Signal Amplification. ACS Appl. Mater. Interfaces. 2018, 10, 7852-7858.

(6) Hu, F. C.; Xu, J. Y.; Chen, Y. Surface Plasmon Resonance Imaging Detection of Sub-femtomolar MicroRNA. Anal. Chem. 2017, 89, 10071-10077.

(7) Feng, Q. M.; Shen, Y. Z.; Li, M. X.; Zhang, Z. L.; Zhao, W.; Xu, J. J.; Chen, H. Y. Dual-wavelength Electrochemiluminescence Ratiometry based on Resonance Energy Transfer between Au Nanoparticles Functionalized g- $\mathrm{C}_{3} \mathrm{~N}_{4}$ Nanosheet and $\mathrm{Ru}(\mathrm{bpy})_{32}{ }^{+}$ for MicroRNA Detection. Anal. Chem. 2016, 88, 937-944

(8) Shen, Z. Fa.; Li, F.; Jiang, Y. F.; Chen, C.; Xu, H.; Li, C. C.; Yang, Z.; Wu, Z. S. Palindromic Molecule Beacon-Based Cascade Amplification for Colorimetric Detection of Cancer Genes. Anal. Chem. 2018, 90, 3335-3340.

(9) Liu, S. S; Cao, H. J.; Wang, X. Y.; Tu, W. W.; Dai, Z. H. Green Light Excited Ultrasensitive Photoelectrochemical Biosensing for MicroRNA at a Low Applied Potential based on the Dual Role of AuNPs in $\mathrm{TiO}_{2}$ Nanorods/AuNPs Composites. Nanoscale. 2018, 10, 16474-16478. 